\title{
Semantic Learning Designs: Recording Assumptions and Guidelines
}

\author{
Miguel-Angel Sicilia \\ University of Alcalá, Spain \\ msicilia@uah.es
}

\begin{abstract}
Recent developments in the standardization of learning technology have resulted in models of learning activities and resources including descriptive metadata and definitions of conditional flows for multi-role activities. Nonetheless, such learning designs are actually representations of the results of the design process and do not provide information about the rationale of the design, i.e. about the theoretical standpoints, assumptions or guidelines applied to come up with the concrete arrangement of activities. These latter elements are critical not only for informative reasons, but as a medium towards the end of connecting theories and hypotheses to actual practice and analyzing the resulting empirical data as a form of inquiry on the validity of theoretical assumptions. This paper delineates the main aspects of a schema for the recording of such design rationales using an ontological approach. The method for the engineering of the schema was based on connecting the definitions provided with an existing large ontological base, thus reusing a large amount of commonsense knowledge. Two paradigmatic example positions of the range of aspects that could be covered by the representation language are described as an illustration. The resulting ontological definitions can be used as a foundation for the refinement of theoretical positions and for their comparative assessment.
\end{abstract}

\section{Introduction}

The recent evolution and growth of on-line learning activities of a diverse kind has resulted in new practices and conceptual paradigms for the crafting of learning resources and learning programs. This includes specific knowledge that applies to the design of e-learning materials and activities. For example, Brown and Voltz (2005) have recently summarized some of them, ranging from technological to social or cognitive, and Conole et al. (2004) have provided a model for designing e-learning activities from different theoretical positions. In addition, learning technology standards that model learning contents and activities (Friesen, 2005) provide enhanced opportunities for the reuse of diverse kinds of resources, stemming from the concept of learning object (Wiley, 2001; Polsani, 2003). These resources range from self-standing educational 
materials to complex learning activity designs encompassing the interaction of several roles and being driven by rules explicitly provided to guide the flow of activities.

Concretely, the increasing adoption of the IMS Learning Design (LD) ${ }^{1}$ specification has provided a standardized common ground to the representation of learning designs in digital form. An activity in IMS LD is considered as a piece of interaction among a number of specified roles - played by persons in instantiations of each concrete LD that produce a tangible outcome by using a concrete environment. The environment is in turn made up of learning objects (McGreal, 2004) and services (i.e. facilities available at runtime, as, for example, a chat room). Activities can be further decomposed in subactivities, and they are aggregated into methods, that specify the conditions for application of the learning design, along with the planned objectives that will eventually match the outcomes of the activities. Methods can be structured around concurrent plays and these in turn can be structured in sequential acts, the latter allowing the specification of conditional execution. This schematic description of LD gives an idea of the flexibility the specification provides in describing activity-based learning programs, as acknowledged elsewhere (Allert, 2004). IMS combined with learning object-oriented specifications as IEEE LOM (IEEE, 2002) and ADL-SCORM ${ }^{2}$ enable a degree of representation of activities and materials with unprecedented applications.

As can be appreciated from the above discussion, there exists a growing consensus on a concrete terminology and model for creating metadata describing learning activities and their associated constituents, and at least general principles for their design are yet available. Nonetheless, while this is enough for describing the activities by themselves, a richer framework is required to capture also the intellectual process that was involved in their crafting, i.e. the hypotheses, assumptions and decisions that led to the concrete arrangement of activities and conditions. Doing so will expand the current scope of metadata-described learning resources from the description of the activities themselves to the description of the designer's intentions. It may be argued that such kind of knowledge is difficult to capture due to the heterogeneity of theoretical standpoints and also due to the use of "tacit" knowledge or little reflexive designs that could be found in many designs. But the benefits available for researchers and practitioners in general are still important enough to deserve the effort, and in fact toolkits as the one described by Conole et al. (2004) consider design theories explicitly, and can be used as a point of departure. The benefits of recording the rationale for learning designs is complementary to the post-activity analysis of the actual history and outcomes of activities in actual settings, which has been pointed out as a relevant source of empirical information (Koper, 2004) that will eventually be available in the coming years.

More concretely, the modelling of the rationale of learning designs would provide a number of benefits for researchers and educators in general. Among these benefits, Sicilia and Lytras (2005) provided the following list: (a) the linking of theoretical assumptions to practical learning designs for informative purposes, (b) the use of such links as resources for education of learning designers, (c) the search for patterns in design

\footnotetext{
${ }^{1}$ http://www.imsproject.org

2 http://www.adlnet.org
} 
situations that include some given theoretical assumptions and (d) the "inference" of detailed comparisons between the effectiveness and adequacy of learning designs (for similar settings). These aspects are reflections of the practical benefits of the main objective of the recording of design rationales, which is no other than advancing the scientific inquiry on learning by enabling the recording of explicit links from design rules to concrete designs, and the latter to the outcomes of the "instantiation" of these designs in possibly diverse institutions or groups. This would come up with an unprecedented empirical base for meta-analysis and knowledge discovery. For example, hypotheses on the adequacy of group-based or individual learning for some given conditions could be tested with a large empirical base containing the history of interaction and resutls of multiple similar learning programs.

This paper approaches the problem of the metadata representation of assumptions and hypothesis related to learning designs in a general sense. Since the entities to be represented are relevant rules or rationales involved in the intellectual process of designing learning experiences, the schema described is deliberately open-ended. This is a requirement imposed by the fact that theories and guidelines related to learning are based on models that are abstract in nature. This in turn is because they attempt to characterize learning as a general human cognitive process, but there exist at least some recurring elements that are common to many practical learning designs. We have not attempted to build an ontology of existing theories of learning, but addressing some "upper" elements that cross-cut any of them, e.g. notions of change are one of these upper elements (Sicilia and Lytras, 2005). In any case, the fact that diverging accounts of learning exist is far from controversial, and even modern theories somewhat diverge in their basic ontological commitments (Packer and Goicoechea, 2000).

The representation described departs from a model based on IMS LD but expressed in a richer ontological language. Ontology engineering (Gruber, 1995) provides a method to develop semantic conceptualizations, and Semantic Web technology (Berners-Lee, Hendler and Lassila, 2001) aims at providing tools and techniques to develop software that exploits them in the context of a learning system. Formal ontology provides the knowledge representation infrastructure for ontologies of learning to a level of considerable complexity and richness, as supported by description logics (Baader et al., 2003). It should be noted that the "ontology of learning" explicitly or tacitly assumed actually constraints and drives the behaviour of the system as a whole, and the criteria used for the evaluation of the outcomes of activities also become a reflection of previous ontological commitments. For example, an ontology not considering social issues will not allow (or will not care about) the tracking of the evolution that takes place in the social network of the learners involved as the activities are carried out.

The resulting learning design descriptions are called here "semantic learning designs" to represent the fact that they are described in ontological terms, and that the meaning of the design as conceived by the designer is explicitly represented. This carries one step further the current metadata descriptions provided by specifications as LOM, SCORM or LD. 
As a technique for validating the semantic precision of the schema described here, explicit links have been provided to concepts and relations that are already described in a large upper ontology, concretely, the OpenCyc 0.9 knowledge base. This is an alternative to analysis techniques as the Bunge-Wand-Weber (Wand and Weber, 1995) that fosters the reuse of existing open knowledge engineering. The subsequent mapping to modern Web-enabled ontology languages as $\mathrm{OWL}^{3}$ is a straightforward step. In addition, some representative examples of different theoretical standpoints are described as illustrations.

The rest of this paper is structured as follows. Section 2 provides an ontological account of an activity-based model of learning activities as supported by IMS LD, which constitutes the artefact that was created by an intellectual process. Then, Section 3 describes a proposal for an ontological schema targeted at recording design rationales in a broad sense. The scheme described is then used in the fourth section to provide as a case study the comparison of two theoretical frameworks that lead to two different descriptions for a concrete learning design. Finally, conclusions and future research directions are provided in the fifth section.

\section{Recording educational metadata and semantic annotation of learning activities}

The first step in the modelling of learning design rationales is that of representing the results or artefacts of the design process. In this section, the main elements of the IMS LD schema are expressed in ontological terms, considering both the design in itself (i.e. the equivalent to an LD description) and the entities that result from the application of designs in actual occurrences of learning following them (i.e. the recording of actual executions of the planned design in concrete instructional or training settings).

A significant amount of reuse in terminological structures can be achieved by building conceptualizations on top of existing large terminological bases like OpenCyct. OpenCyc is the open source version of the Cyc Knowledge Base (Lenat, 1994), which contains over one hundred thousands atomic terms, and is provided with an associated efficient inference engine. $C y c$ uses as its underlying definition language a variant of predicate calculus called $C y c L$, and it attempts to provide a comprehensive upper ontology of "commonsense" knowledge. In the rest of the paper, the ontological definitions provided are explicitly linked to OpenCyc definitions ${ }^{5}$ as a means to reuse existing ontological engineering efforts and also as a way of validating the concepts being represented.

\section{Describing the main structural elements of IMS LD}

\footnotetext{
${ }^{3}$ http://www.w3.org/TR/owl-ref/

${ }^{4}$ http://www.opencyc.org

${ }^{5}$ Ontological definitions of terms and relations are provided in courier font, and those that are defined in OpenCyc are prefixed by "oc".
} 
The conceptual model of IMS LD (IMS, 2003) provides a concise 'meta-language' that could capture a diversity of pedagogical approaches. In doing so, it essentially adheres to an activity-centred paradigm (Allert, 2004). It should be noted that this model is neutral to specific learning theories. Even though it integrates the hierarchical structure of activities and mediation principles of Activity Theory (Kaptelinin, Kuutti and Bannon, 1995), it is actually a meta-language that does not make assumptions about other elements of such theory as the internalization/externalization differentiation.

The first step in developing an ontological schema for IMS LD must be that of clarifying the main entities to be represented. OpenCyc provides a rich framework to describe temporal activities, concretely, the oc_PurposefulAction concept (a kind of oc_Event) defined as "an action consciously, volitionally, and purposefully done by at least one actor" captures the essence of learning activities, which are the ultimate target of the specification. Nonetheless, IMS LD metadata does not attempt to representing the activities as actually enacted by persons, but they describe blueprints that will eventually be bound to one or several instantiations of activities, and they are intended to be searched as such (Buzza et al., 2005). In contrast, oc_Events and their associated entities are related to instantiations and not to their specifications. Further, the concept of oc_ActorSlot represents the specific roles played by persons in events, so that this could be used to represent the LD staff and learner role category, but they do not represent roles understood as templates for their eventual binding to concrete people.

An alternative to representing LD specifications as blueprints is that of creating Event types for each activity defined in a learning design. But this approach entails at least two problems. On the one hand, this is not ontologically correct since it does not represent the reality that the production of IMS LD is an act of creating specification artefacts, instead of a process of classification of possible real world entities. In fact, many learning designs will probably be never executed, and some of them may be purposefully created as mere design examples. And on the other hand, the direct creation of learning designs as ontology terms entails that the activities actually performed must adhere strictly to the original learning design used, which severely restricts the flexibility in using the design with ad hoc changes or modifications (or even modified versions). This second practical flaw suggests that LD specifications should be represented as separated entities.

This has leaded us to the major decision of modelling learning designs as specifications, following the definition of oc_specification, as "an abstract work that constitutes a description of the properties of a Situation or a SomethingExisting, and sometimes even entire collections of such things". Table 1 summarizes the representation of Learning Designs in terms of specifications (specializations of oc_Specification), their main related properties and the implications of each of the specifications when producing actual activities". The concepts of "learning design" and "method" can be considered as equivalent from an ontological perspective, since the former allow one and only one instance of the latter, with no particular logical differences.

\footnotetext{
${ }^{6}$ Notifications and completion conditions are omitted for brevity.
} 


\begin{tabular}{|c|c|c|}
\hline Concept & Main descriptions & Consequences in actual activities \\
\hline Method-Spec & $\begin{array}{l}\text { Objectives and prerequisites } \\
\text { (described in the following section). } \\
\text { Structured in play specifications or } \\
\text { directly act specifications. }\end{array}$ & $\begin{array}{l}\text { Instantiation is an independent, } \\
\text { meaningful learning activity. Plays are } \\
\text { cotemporal oc_subEvents subsumed in } \\
\text { the method. Note that the semantic } \\
\text { definition of subevents yet entails the } \\
\text { subsuming of sub-events in the } \\
\text { containing event. }\end{array}$ \\
\hline Play-Spec & $\begin{array}{l}\text { Collection of sequential acts that } \\
\text { comprise the play. }\end{array}$ & $\begin{array}{l}\text { Since plays are potentially concurrent, } \\
\text { there are not further temporal } \\
\text { restrictions. }\end{array}$ \\
\hline Act-Spec & $\begin{array}{l}\text { Collection of concurrent role parts } \\
\text { that detail the activities included in } \\
\text { the design. Role parts and } \\
\text { environments are the main elements } \\
\text { related to acts. }\end{array}$ & $\begin{array}{l}\text { The sequence of instantiations of acts } \\
\text { could be sequenced through the oc_ } \\
\text { startsAfterEndingof. }\end{array}$ \\
\hline Role-Part-Spec & $\begin{array}{l}\text { The linking of role specifications to } \\
\text { concrete activities or activity } \\
\text { structures. }\end{array}$ & $\begin{array}{l}\text { This entity is not required in the } \\
\text { ontological schema since the } \\
\text { participation of roles in the activities } \\
\text { can be stated in terms of specifications } \\
\text { of oc_ActorRoles, or subevents that } \\
\text { have not a temporal nature. }\end{array}$ \\
\hline Activity-Spec & $\begin{array}{l}\text { The specification of learning and } \\
\text { support structures, in terms of Role- } \\
\text { Specs, ibtUsed Learningobjects } \\
\text { and used Services. Concrete } \\
\text { objectives can also be attached. }\end{array}$ & $\begin{array}{l}\text { Each instantiation of an Activity- } \\
\text { Spec will result in instances of specific } \\
\text { types of oc_Activity. Following LD } \\
\text { specs, support activities instantiate for } \\
\text { every role mapping, while learning } \\
\text { ones instantiate for all the role } \\
\text { mappings. }\end{array}$ \\
\hline Environment & \multicolumn{2}{|c|}{$\begin{array}{l}\text { These are descriptions of learning objects and services that do not require an } \\
\text { explicit mapping in the ontological schema. }\end{array}$} \\
\hline Service & $\begin{array}{l}\text { Service facilities have to be } \\
\text { "instantiated by a local runtime } \\
\text { services", e.g. a chat or discussion } \\
\text { forum. Their computational nature } \\
\text { can be described in terms of concrete } \\
\text { oc_ComputerProgramcw. } \\
\text { Subcategories of such conceptual } \\
\text { representations of software entities } \\
\text { can be used for the typology of } \\
\text { services. }\end{array}$ & $\begin{array}{l}\text { The oc_ComputerProcessRunning } \\
\text { term is used to describe executions of } \\
\text { oc_ComputerProgramcw, which cover } \\
\text { every instance of a service as } \\
\text { understood in IMS LD. The linking } \\
\text { between conceptual and actual running } \\
\text { instances is covered by the required } \\
\text { predicate oc-programofProcess. }\end{array}$ \\
\hline Learning object & $\begin{array}{l}\text { Those descriptions provided by } \\
\text { learning object metadata. Learning } \\
\text { objects can be defined as oc_IBTs as } \\
\text { described in (Sicilia et al., 2005), and } \\
\text { approaches to describing metadata } \\
\text { through ontologies yet exist - see an } \\
\text { overview in (Sicilia and García, 2005) }\end{array}$ & $\begin{array}{l}\text { The learning objects selected are } \\
\text { represented as instances in the } \\
\text { ontology, which are declared to be } \\
\text { used in activities through the ibtused } \\
\text { predicate. }\end{array}$ \\
\hline Role-Spec & $\begin{array}{l}\text { Describe stereotypical actors of } \\
\text { learning and support activities. These }\end{array}$ & $\begin{array}{l}\text { Role specs are mapped to actual users } \\
\text { when the activities take place. This is }\end{array}$ \\
\hline
\end{tabular}




\begin{tabular}{|l|l|l|}
\hline & $\begin{array}{l}\text { act as "contract" for the actual } \\
\text { participants, in the sense provided by } \\
\text { Sánchez-Alonso and Sicilia (2004). }\end{array}$ & $\begin{array}{l}\text { mapped to predicates of the class } \\
\text { oc_ActorRole. }\end{array}$ \\
\hline
\end{tabular}

Table 1. Summary of the main specification definitions in the ontological schema

As described in Table 1, the OpenCyc built-in support for modelling temporal events can be used to express the coordination relationships between the constituents of the units of learning. The actual instances of learning events will be modelled as instances of oc_Learning "The collection of all events, brief or extended, in which an agent is acquiring information or know-how", and more specifically, as instances of an specialization computerMediatedLearning, simply requiring the use of information networks for at least part of the learning activities. Since events in OpenCyc are also situations, they have components in addition to the temporal extent, including people involved, information things used and other arrangements.

Figure $1 \mathrm{~b}$ depicts the main elements that describe actual current or past enactments of activities. The schema is based on a clear separation of the specifications and the actual activities that by itself constitutes a metadata layering. OpenCyc predicates as oc_situationConformstoSpecification allows the linking of situations (every action is a situation also) to the specifications they conform - be it purposely or not. The LD-Activity term has been introduced as the common category of learning and support activities. Methods, plays and acts become special sub-categories of LDActivity, and the constituent activities of Acts are instances of LD Activity also. Roles are attached to any kind of LD Activity, even though it is required for the low-level structure. The LD concept of "activity structure" as an aggregation of activities does not require an explicit modelling due to the generic mereology of activities engineered in OpenCyc.

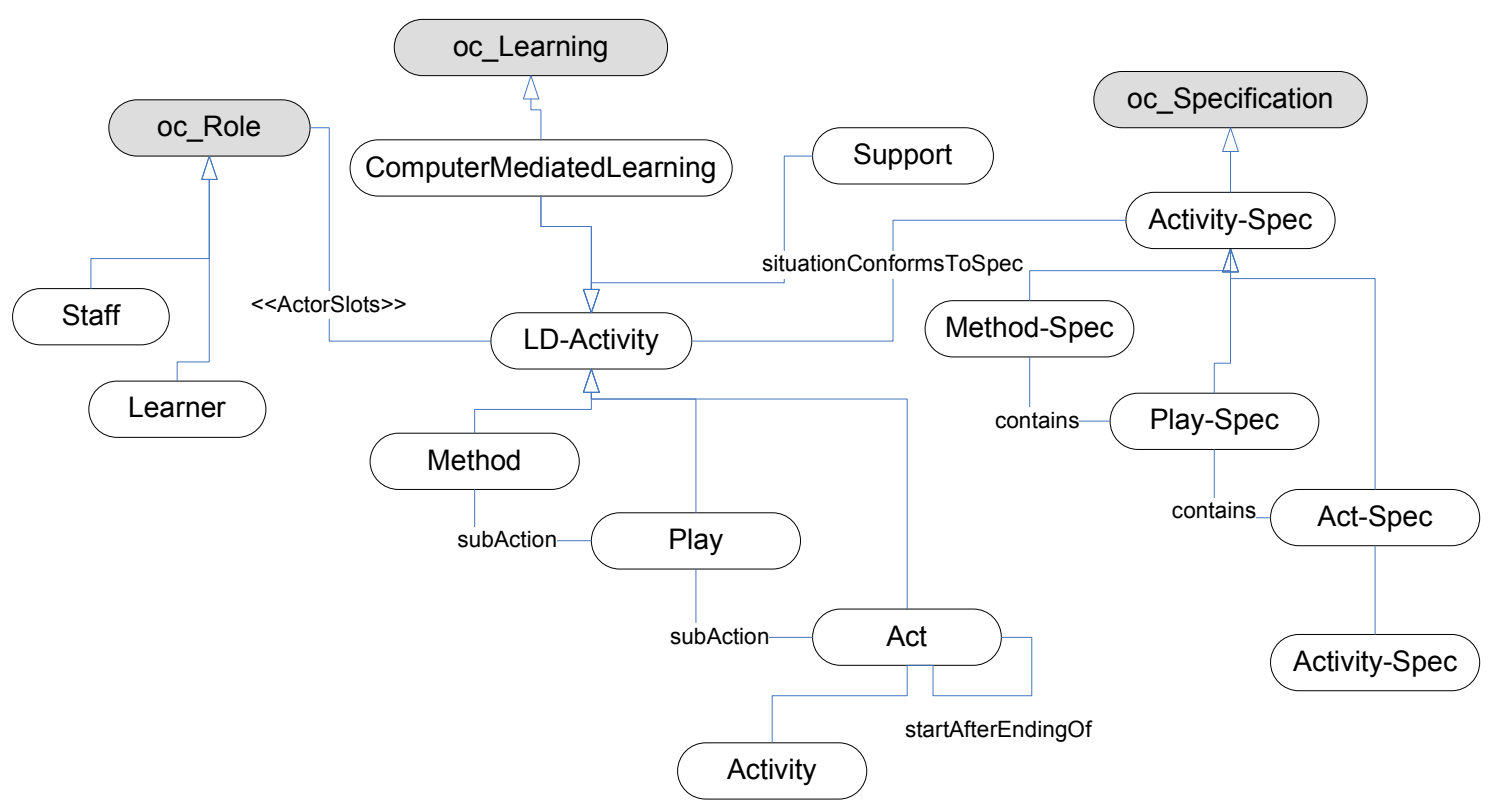

Figure $1 \mathrm{~b}$. Summary of the main activity-role definitions in the ontological schema 
The concept of oc_Role accounts for participant roles but also for other kinds of "components". This is why two specializations of the concept of oc_Actorslot, labelled Staff and Learner are required to differentiate participants from other elements. As is obvious from the above discussion, the built-in representation of activities in OpenCyc is powerful enough for the definition of LD activities.

The final part of the ontological specification described so far is that of the mapping from Learning Design specifications to the actual past or present activity realizations. The oc_situationConformstospecification predicate can be used to trace which activity realizations come from a given LD activity definition, and the same occurs with the oc_thingspecified for other LD elements as roles or environments. Existing LD execution engines as CopperCore ${ }^{7}$ actually map LD specs to on/line collaboration, so that the translation of the ontological representations of LDs to ontology definitions of activities is straightforward following similar representation.

\section{Describing objectives, outcomes and pre-conditions}

According to IMS LD learning objectives and prerequisites "can be described using the IMS Reusable Definition of Competency or Educational Objective (RDCEO) format, but can also refer to simple resources (e.g., a text) with a description of the learning objective". Since the latter option is not useful from the viewpoint of computational semantics, we will adhere to the former. As commented above, the competency view is not exclusive to other kinds of objectives related to other ontological standpoints (Sicilia and Lytras, 2005), and other conceptions of change or improvement may include social ties, cognitive structures or the combination of the knowledge of a group. In fact, competencies adhere mostly to behaviouristic frameworks that focus on observable, external behaviour (Tennant, 1991) rather than in cognitive representations. Nonetheless, the discussion below is equally applicable to other kinds of objectives, so that we will adhere to the competency view.

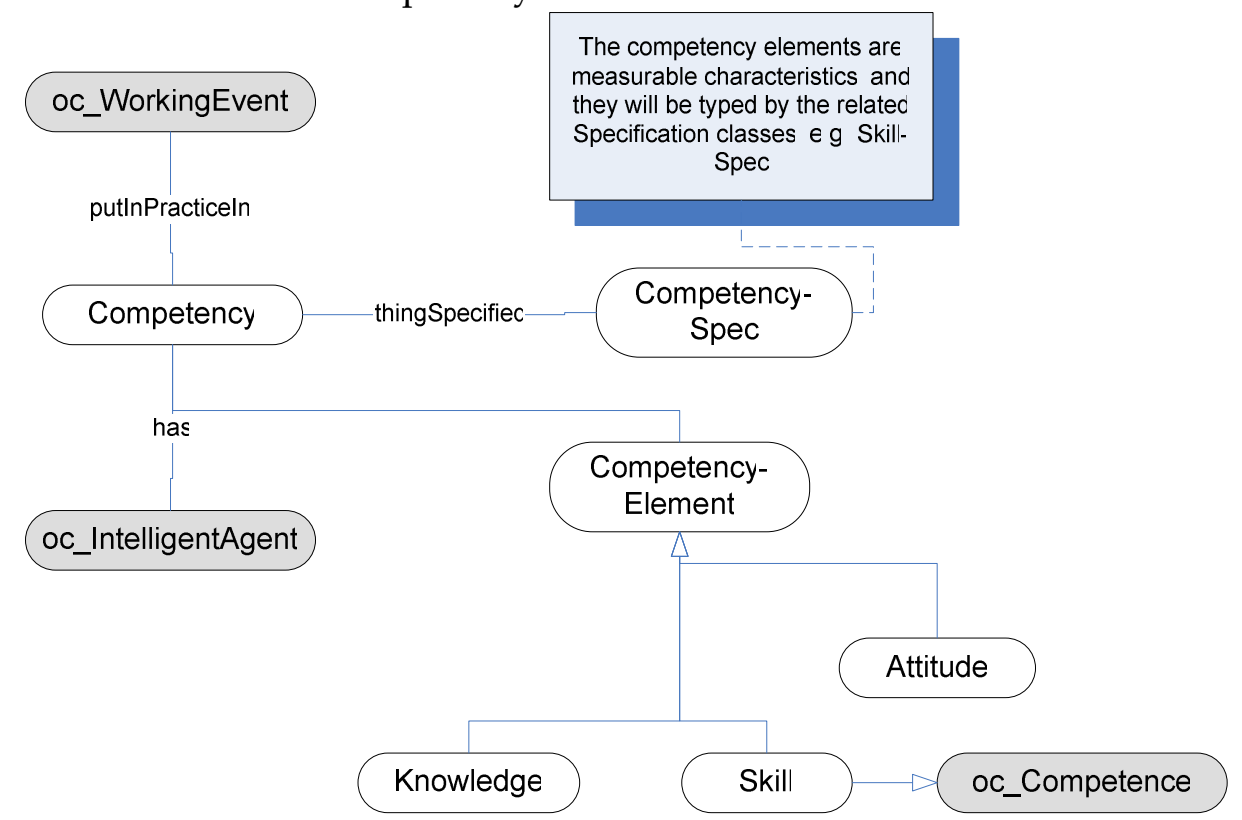

Figure 1a. Summary of the competency components in the ontological schema

\footnotetext{
${ }^{7}$ http://coppercore.org/
} 
oc_competence in OpenCyc is defined as a quantity that "for describing the level of skill with which an agent performs some task". This does not remove the lack of precision that are yet present in RDCEO definitions, as described by Sicilia (2005). As an alternative, Figure 1a provides a simplified account of the model described by Sicilia, as related to OpenCyc terms, in which competence is integrated as one of the elements of the broader notion of competency, according to the model of according to the model of Rummel (Rothwell \& Kazanas, 1992), which considers work situations, attributes of the individual that are applied in such situations and measurement with respect to some standard of performance. The most relevant distinction is again the separation of actual competency representations and competency "definitions" (i.e. specifications) intended to provide a type structure to competencies to be used in objective or precondition specification. In this case, the generic oc-thingspecified predicate can be used for the linking of both levels of representation.

Objectives and preconditions can then be expressed as formulas on the acquisition of competencies or their components (competency elements). Descriptions specific to OpenCyc may use oc_CycLSentence-Assertible, but simpler enumeration of competency components could be used instead.

\section{Describing learning design rationales: theories, hypotheses, guidelines and rules}

The concept of "design" for our purposes is properly captured in the $5 a$ definition provided in the Merriam Webster Online Dictionary: "an underlying scheme that governs functioning, developing, or unfolding". In consequence, learning designs refer to artefacts, and not to the process of devising the educational solution. This is equivalent to the concept oc_Design, subsumed by the notion of oc_Specification which is described as "an abstract work that constitutes a description of the properties of a Situation or a SomethingExisting, and sometimes even entire collections of such things." In consequence, the term LearningDesign would simply delineate a subset of specifications that are oriented to describe how learning experiences with concrete objectives should be. Trivially, oc_Designer describes the authors of the learning designs, and oc_Designing represent the oc_HumanActivity that leads to the production of learning designs. Designing as a special kind of activity is carried out (oc_doneBy) by a designer, which provides a way to attach meta-information about the rationale of the design.

From an ontological perspective, the departing problem in modelling learning design rationales is that their assumptions and hypotheses of different theoretical standpoints need not be compatible or need not consider the same aspects of reality (Packer and Goicoechea, 2000; Coner et al., 2004). Furthermore, different pedagogical approaches are known to result in different mappings to activities (Coner at al., 2004). This would either require the provision of separate ontologies or the use of a representational mechanism that allows such kind of potential inconsistency or divergence. The concept 
of microtheory in OpenCyc provides such representational mechanism, intended to organize assertions that depend on "shared set of assumptions on which the truth of the assertions depends". Definitions inside the same microtheory need to be consistent, but this is not required across microtheories. The descriptions provided in the above section can be used as a base microtheory called LearningActivitiesMt for others that are specific to concrete theoretical frameworks. In this section, we will describe elements that are common to the description of theoretical frameworks, so there will not be a distinction of microtheories.

The intellectual processes of learning design in themselves will be represented as oc_Designing activities, carried out by oc_Designers. An additional consideration is that the information about the rationale of the design would be better attached to representations of each of the design processes (i.e. to oc_Designing instances) than to the final design. This enables the registering of different assumptions for different contributions to the same artefact, e.g. different revisions from the same of different designers.

Several designers may participate in the same designing activity, and formal frameworks for collaborative learning resource creation (Dodero, Aedo and Díaz, 2002) can be integrated by clearly specifying which class of things can be the outcome of a designing process. For the sake of flexibility, the concept of LearningDesignPart is introduced as an all-encompassing category that includes every of the elements described in the previous section. This includes activities and roles, but also objectives, conditions and the like. Furthermore, the granularity of the descriptions allows for different levels, from considering a unique designing activity for the whole package to recording each element of the learning design comprehensively. Since oc_Actions are subsumed by the concept of oc_Event, considered as "dynamic situation in which the state of the world changes", each edition of a metadata record or any other form of description may be subject to be described. The concept is flexible enough to be able to record finegrained, detailed decisions. This of course may include different versions of the same artefacts, but this is an orthogonal aspect of configuration that is no relevant for our present discussion.

Figure 2 depicts the main elements of the loci to which rationales, assumptions and guidelines will be attached.

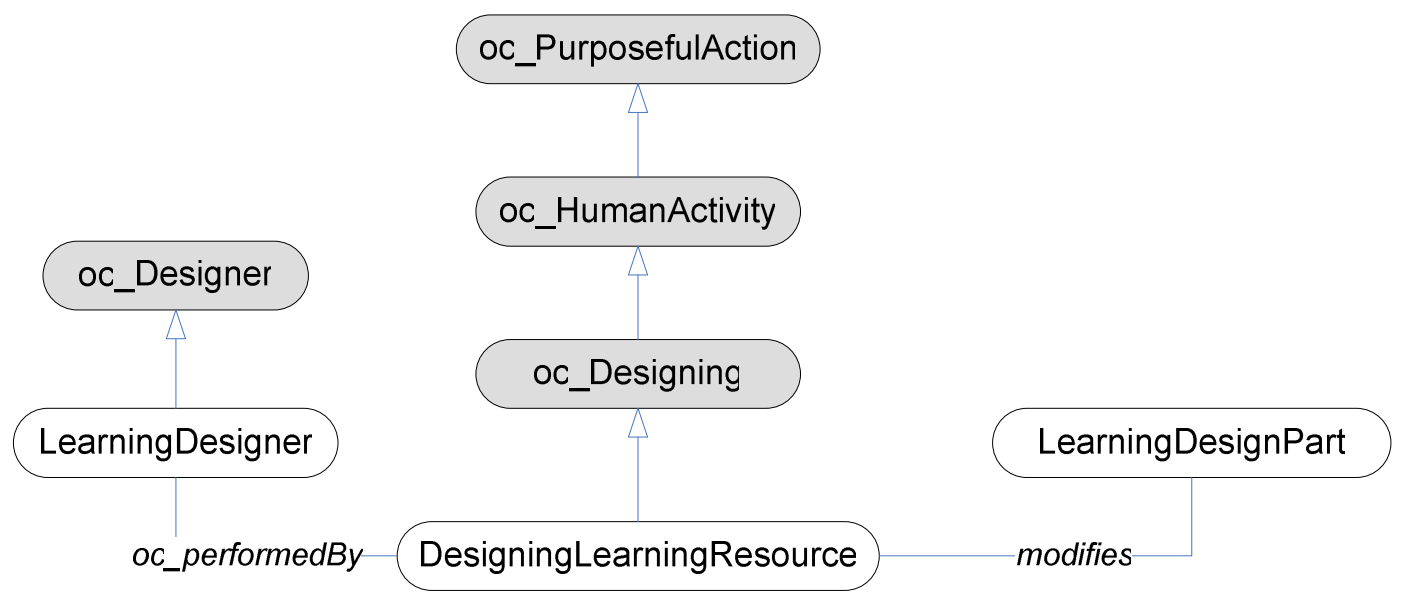

Figure 2. Main elements of the ontological schema for the loci of design rationales. 
A LearningDesigner can be defined as the class of humans ${ }^{8}$ that perform activities of learning resource design. The concept oc_Designing is a subclass of the concept oc ThinkingAboutTheStateofTheWorld, which represents "thinking processes", which include mental events as planning, evaluating or inventing. Thus, the concept of design described so far should be understood in terms of the concept of "expanded rationality" as described by Hatchuel (2002), integrating creativity and unexpected expansions of the original requirements. This precludes ontological definitions in which the problem space is completely bounded a priori. In consequence, a degree of openness is necessary to integrate different kinds of detail in description, from fully described ones to others with shallower semantics, e.g. some providing only references to generic assumptions.

\section{Theoretical frameworks}

We will make the distinction that guidelines (as defined below) are the propositions that directly predicate about the validity or appropriateness of learning design parts, while other theoretical propositions about learning that are not directly saying anything about the design of digital learning resources are considered as assumptions, following the general sense provided in the MW dictionary "a fact or statement (as a proposition, axiom, postulate, or notion) taken for granted".

The fact that some assumption, hypotheses or proposed law about learning is sustained by a broader empirical base or is better sustained by rational means is out of the scope of this work since here we focus on design practice (even though it is of an obvious interest for researchers). In principle, even unorthodox positions may be sustained, since the mechanism of microtheories and their inclusion mechanism allows for a great flexibility in modelling them.

Table 1 provides some examples of theoretical assumptions and related guidelines for "extreme" archetypical standpoints on learning. These are not intended to reflect actual common positions, but they are provided as illustrative examples of radical positions that could be modelled with our ontological schema.

\begin{tabular}{|l|l|l|}
\hline $\begin{array}{l}\text { Archetypical } \\
\text { standpoint }\end{array}$ & Assumptions & Example guidelines \\
\hline $\begin{array}{l}\text { Instructivist } \\
\text { (behaviouristic) }\end{array}$ & $\begin{array}{l}\text { Learning occurs through association } \\
\text { and reinforcement. } \\
\text { The results of learning can be } \\
\text { appreciated through observable } \\
\text { outcomes. }\end{array}$ & $\begin{array}{l}\text { (GB1) Every instance of oc-Learning } \\
\text { entails the exposure to some } \\
\text { LearningObject that produces the } \\
\text { association. } \\
\text { (GB2) Learning Activity sequences } \\
\text { should provide assessment activities that } \\
\text { confirm the associations that should have } \\
\text { been established so far. }\end{array}$ \\
\hline Constructivist & $\begin{array}{l}\text { Learning proceeds by building } \\
\text { mental structures. }\end{array}$ & $\begin{array}{l}\text { (GC1) Agent's mental structures should be } \\
\text { represented. } \\
\text { (GC2) These structures should be pre- } \\
\text { assessed in order to be comparable with }\end{array}$ \\
\hline
\end{tabular}

\footnotetext{
8 The consideration of learning design as a unique human activity could be considered as restrictive of intelligent software for the task. Simply changing the oc_Designer class to a subconcept of oc_IntelligentAgent could remove this, but this entails a change in OpenCyc knowledge base.
} 


\begin{tabular}{|l|l|l|}
\hline & & $\begin{array}{l}\text { the resulting ones. } \\
\text { (GC3) Design Activities are } \\
\text { recommended. } \\
\text { (GC4) Contrast Activities are } \\
\text { recommended. }\end{array}$ \\
\hline Socio-cultural & $\begin{array}{l}\text { Learning occurs through social } \\
\text { participation }\end{array}$ & $\begin{array}{l}\text { GSC1) Every instance of oc-Learning } \\
\text { entails the interaction of several oc- } \\
\text { IntelligentAgents as oc-Actors. }\end{array}$ \\
\hline
\end{tabular}

Table 1. Some examples of theoretical assumptions and guidelines

The examples provided in Table 1 go a step further than toolkits as Conole's et al. in making the design rationale explicit. Nonetheless, in many cases "commonsense" is applied to design and a shallower approach to specification could be used instead, e.g. providing simply links to the theoretical standpoints used. It should be noted also that the resulting guidelines vary greatly in their level of concreteness and some of them may be considered as mandatory from some standpoints, while others are mere general representations. This would lead to different computational strategies.

\section{Guidelines and rules}

The WordNet thesaurus defines guidelines as "guidance relative to setting standards or determining a course of action" or "a rule or principle that provides guidance to appropriate behavior". In our case, guidelines are statements that serve as criteria for decision in designing learning. Given that e-learning design is still far from being a mature discipline, Guidelines, as instances of recorded knowledge, can be characterized as oc_NormativeSpecifications, since they describe how learning resource design activities and their outcomes "should be", in a propositional form. Propositions "have some truth value in some context or 'world". . Furthermore, propositions "are assumed to be representable (at least in principle) by a sentence in some formal or natural language". This raises the need for a language that express guidelines in a general sense. There are two main options for such representation, be them formal logical sentences or reified guidelines.

Formal logical sentence representation entails the formalization through sentences of the constraints of the designs. For example, if "every learning resource may be active" according to some theoretical standpoint (e.g. one that fosters reflective learning), this sentence may be represented as an axiom and put into the appropriate, separate microtheory as the following $C y c L$ fragment:

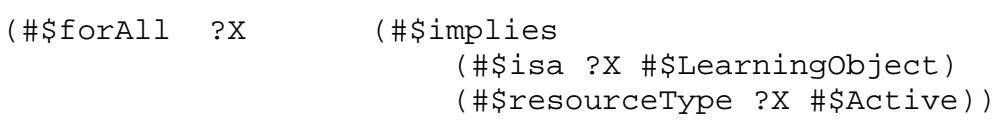

Then, resources that are not active are simply excluded from the notion itself. This is a strong position in the sense that precludes some views on the learning design process. Another typical example may be that of a socio-cultural guideline that preclude Methods that do not entail multi-role activities that provide access to social interaction Services. This approach to guidelines provides the best framework for automation and would enable the creation of microtheories that represent clearly formulated views on learning. Nonetheless, there are two major problems for the use of this option as the unique mechanism for encoding design rationales: 
1. There is not a clear-cut distinction between models and theories of learning, since they come from a history of schools of though with interrelations (Palmer, 2001). This would lead to the need for the representation of dozens of variants reflecting positions that only diverge in some aspects.

2. Many guidelines can not be represented as logical sentences since they represent "recommendations" or vague requirements, e.g. see (GC3) or (GC4) above.

These issues suggest that a combination of formal sentences with reified guidelines provide the best option for flexibility. The representation of guidelines has been studied in the field of Human-Computer-Interaction (HCI) in the last decade (Vanderdonckt, 1999), and the main philosophy of such representations remains valid in the learning design domain. The major challenge for such representations is that of providing computational semantics that could be used for the implementation of software support, but this is difficult to attain in all the cases. Thus the concept of learning design guideline will provide two kinds of representations: general and schema-specific.

The general use of instances of oc_NormativeSpecification allows the modelling of "conceptual works that describe how something should be". This may include representation of known normative representations or procedures. For example, one may refer to a concrete learning design model as that derived from Bannister (1981), which states that creativity cycles follow an initial phase of brainstorming (idea capture), followed by a phase in which key issues are focused into an operation strategy (idea development) and a third phase in which project control takes place through a "recursive cycle" (operational management). The reference could be made by pointing to the academic reference describing it as a conceptual work, or it could be described as an Activity-Spec modelled explicitly inside the ontology. As another example, some detailed guidelines could be modelled by the normative specification sub-category of oc-Instructions, defined as "a sequence of tasks to be performed by an agent".

Schema-specific guidelines restrict the freedom to represent criteria as conceptual work instances to a concrete and commonly agreed ontology that determine what can be said about how learning designs should be according to a theoretical standpoint or framework. These build on an activity-role ontology as the one described in the above section, and add a prescription on the kind of "should-be" predications that are allowable. The following Table describes examples of a minimal language that could be used for that purpose.

\begin{tabular}{|l|l|l|}
\hline Sentence type & Potential uses & Example \\
\hline $\begin{array}{l}\text { Recommendation } \\
\text { shouldBe } \\
\text { SENT) }\end{array}$ & Recommend kinds of activities & $\begin{array}{l}\text { Design activities are recommended (GC3). } \\
\text { shouldBe (Method, subEvent (CAT, } \\
\text { DesignActivity)) }\end{array}$ \\
\hline $\begin{array}{l}\text { Obligation } \\
\text { mustBe (CAT, SENT) }\end{array}$ & $\begin{array}{l}\text { Some activity types must } \\
\text { follow others. }\end{array}$ & $\begin{array}{l}\text { Assessments must follow each exposition } \\
\text { to contents (GD1). } \\
\text { mustBe (and (ExpositiveActivity, } \\
\text { IndividualActivity), } \\
\text { startAfterEndingof (CAT, } \\
\text { AssessmentActivity) }\end{array}$ \\
\cline { 2 - 3 } & Activities must have some & $\begin{array}{l}\text { Every activity must entail interaction } \\
\text { mustBe (LDActivity, }\end{array}$ \\
\hline
\end{tabular}




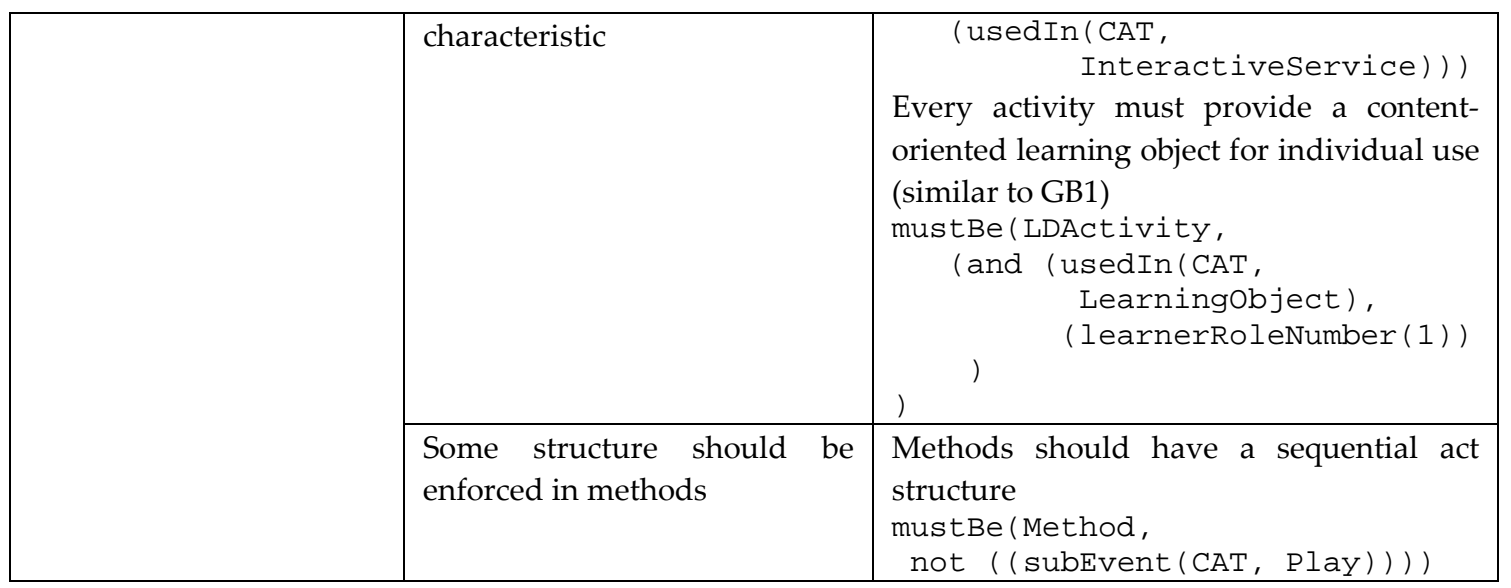

In the examples, CAT represents a category of individual expressed through a concept or a logical formula, and the sentence is a synthetic way of expressing some recommended or mandatory constraint over such category. Other languages could be engineered in further research, but the one described can be directly expressed in OpenCyc and combined with software modules that check or enforce them in some way. Note that this representation does not use direct OpenCyc sentences, so that reification is used instead of direct logical sentences. It is not the aim of this paper to determine the most powerful and flexible representation language, but only set a foundation for further specification efforts.

\section{Analysis and comparison of two theoretical semantic frameworks}

As an assessment of the representational capabilities of the scheme just described, a case study of representation is sketched in this section. We will use the learning design toolkit described by Conole et al. (2004) as the underlying terminology, even though other frameworks could be used instead.

Two rather diverging positions for design will be used as an illustration. The following Table summarizes the two design scenarios.

\begin{tabular}{|l|l|l|}
\hline Scenario & Description & $\begin{array}{l}\text { Classification according to Conole } \\
\text { et al. toolkit }\end{array}$ \\
\hline $\begin{array}{l}\text { A) } \\
\text { Systemic- } \\
\text { Behaviourist }\end{array}$ & $\begin{array}{l}\text { A software development company attempts to } \\
\text { design learning units about new technologies or } \\
\text { software products for its developer staff. The } \\
\text { design is driven by a cycle of "competency gap } \\
\text { analysis" that models organizational learning in } \\
\text { terms of the aggregated competencies of the } \\
\text { employees - similar to the one described by } \\
\text { Sicilia (2005). }\end{array}$ & $\begin{array}{l}\text { loces of information forms the } \\
\text { bosis and raw material for } \\
\text { learning. Learning is mainly } \\
\text { based on skill learning and } \\
\text { memorization. }\end{array}$ \\
\hline $\begin{array}{l}\text { B) Socio- } \\
\text { cultural }\end{array}$ & $\begin{array}{l}\text { A special interest group (SIG) on a concrete } \\
\text { research topic aims at developing the knowledge } \\
\text { of its members by sharing experiences and } \\
\text { discussing on themes of common interest. }\end{array}$ & $\begin{array}{l}\text { Focuses on the social, where } \\
\text { experience is the main source of } \\
\text { learning. Conscious reflection on } \\
\text { experience is transformed into } \\
\text { learning. }\end{array}$ \\
\hline
\end{tabular}


The following sub-sections sketch the main outcomes of an example learning design process for both scenarios, assuming that the process described by Conole et al. (2004) is used in both situations.

\section{Differences in modelling the design process}

The forces driving the design process in both scenarios are fairly diverging. The design of Scenario A will typically be constrained by a clear target specified in terms of an aggregated competency level, while in Scenario $B$ there are not concrete competencies to be acquired, and the main objective of the design activity would be twofold. On the one hand, the activities are targeted at promoting interchange of ideas, in an attempt to stimulate casual convergence of interest, which is the main value of the culture of the SIG. And on the other hand, the activities have the generic objective of strengthening social ties, which are an important element of cohesion for the undertaking of joint projects.

The following Table describes the main inputs and possible activities and their objectives at a high-level.

\begin{tabular}{|l|l|l|}
\hline Scenario & Design inputs & Activities and their objectives \\
\hline $\begin{array}{l}\text { A) Systemic- } \\
\text { Behaviourist }\end{array}$ & $\begin{array}{l}\text { A formal competency record for } \\
\text { employees, and competency } \\
\text { requirements expressed in } \\
\text { terms of amounts of required } \\
\text { competencies (assuming a } \\
\text { shared measurement scale). } \\
\text { Such requirements are actually } \\
\text { derived from strategy or from } \\
\text { the contingent requirements of } \\
\text { upcoming projects. }\end{array}$ & $\begin{array}{l}\text { level of competency-Spec for the required } \\
\text { competencies (or their constituents). A formal } \\
\text { match considering the agenda of employees is } \\
\text { carried out for determining the target learners. } \\
\text { Learningobjects for individual use are } \\
\text { selected as the main elements of the activities, } \\
\text { and criteria for selection is again a match of } \\
\text { the objectives stated in metadata (as stated in } \\
\text { category 9 of LOM - Classification) and the } \\
\text { competencies required. }\end{array}$ \\
\hline $\begin{array}{l}\text { B) Socio- } \\
\text { cultural }\end{array}$ & $\begin{array}{l}\text { The expertise of the SIG } \\
\text { Members as stated in the } \\
\text { concepts addressed by their } \\
\text { publications, projects or other } \\
\text { activities. }\end{array}$ & $\begin{array}{l}\text { Informal group activities are the main approach } \\
\text { applicable, since there is not a predefined group } \\
\text { structure but a culture of sharing and } \\
\text { socialization. The results of the sharing of ideas } \\
\text { can be expressed in terms of oc-knowsAbout } \\
\text { predicates, and social ties will be modelled } \\
\text { through positive valence FOAF-knows } \\
\text { predicates with an added numerical value } \\
\text { representing strength. }\end{array}$ \\
\hline
\end{tabular}

The changes intended to be achieved in each of the scenarios are stated differently, with a formal definition in (A), and a shallow cognitive and social representation in the case of (B). In addition, case (B) requires a model of social network that is largely irrelevant in case (A).

\footnotetext{
${ }^{9}$ http://xmlns.com/foaf/0.1/
} 


\section{Differences in recording activity rationales}

The approach for the recording of design rationales also differs due to the different contexts. The following Table summarizes the main elements for each of the scenarios.

\begin{tabular}{|c|c|c|}
\hline Scenario & Approach & Examples \\
\hline \multirow[t]{2}{*}{$\begin{array}{l}\text { A) Systemic- } \\
\text { Behaviourist }\end{array}$} & $\begin{array}{l}\text { Formal logical sentences are used } \\
\text { to guarantee that every design } \\
\text { follows an organizational } \\
\text { objective. }\end{array}$ & $\begin{array}{l}\text { It is required that the objective of every Method } \\
\text { is attached to a Competency-Spec instance as } \\
\text { objective. }\end{array}$ \\
\hline & $\begin{array}{l}\text { Formal assessment is a } \\
\text { requirement for accountability } \\
\text { purposes. }\end{array}$ & $\begin{array}{l}\text { Guideline (GD1) is attached to every Designing } \\
\text { LearningResource instance that produces an } \\
\text { Act. }\end{array}$ \\
\hline $\begin{array}{l}\text { B) Socio- } \\
\text { cultural }\end{array}$ & $\begin{array}{l}\text { The interaction in informal } \\
\text { settings can be used to derive } \\
\text { social models (Sicilia and } \\
\text { García, 2004) }\end{array}$ & $\begin{array}{l}\text { The interactions in discussion can be used to } \\
\text { measure the degree of "proximity" between } \\
\text { members. The rationale of the activities can be } \\
\text { justified in terms of socialties inside } \\
\text { Socialnetworks. } \\
\text { Further, the focus of each group activity should } \\
\text { be clearly stated, and a combination of the } \\
\text { increase in collective knowledge and the } \\
\text { strengthening of social relations can be used for } \\
\text { assessment. }\end{array}$ \\
\hline
\end{tabular}

\section{Conclusions and directions for research}

Current technology and practice related to the description of reusable digital learning resources has resulted in techniques that allow the description of learning activities of a complex kind, including their intended participants, educational objectives and execution constraints. The representation and recording of the assumptions and guidelines that were considered in the creation of such resources would extend current techniques to capture the rationale of the design itself. This in turn will eventually result in the availability of a large base of empirical data available in which theoretical assumptions or rules are explicitly connected to the resulting designs, as these could be linked with the actual results and trace of the learning processes that used them. The resulting body of evidence would represent a critical asset in the development of the theory of learning mediated through computers.

This paper has described the first attempt to extend existing learning technology models with a schema explicitly targeted at describing learning design rationales. The OpenCyc knowledge base has been used as the semantic reference from which the ontological schema has been specified. Concretely, an activity-based schema based on IMS LD has been described, and then theoretical assumptions and codified guidelines have been introduced. The flexibility of the representation schema has been analyzed through the representation of two stereotyped theoretical positions.

Two main research directions should continue the work described here. On the one hand, further ontological engineering effort is required to come up with a more comprehensive and rich schema for learning design rationales. And on the other hand, 
tool implementation and record gathering efforts would be required to attain the ultimate objective of the ontological definitions described so far. With such effort, an unprecedented research material could be available in some years, providing improved opportunities for scientific inquiry on design as an activity regarding pedagogy.

Other potential directions for research may be the description of interpretations of the design intentions, for which no rationale was explicitly recorded, the mining or detection of patterns as related to rationale description, or the detailed use of theoretical rationales in agents that support the learning process which represent a category of relevant learning support software (Holmes, 2005).

\section{References}

Allert, H. (2004). Coherent Social Systems for Learning - An Approach for Contextualized and Community-Centred Metadata. In: Anderson, T. and Whitelock, D. (Eds.). The Educational Semantic Web: Visioning and Practicing the Future of Education, Journal of Interactive Media in Education, 2004 (1).

Baader, F., Calvanese, D., McGuinness, D., Nardi, D., Patel-Schneider, P. (eds.). (2003). The Description Logic Handbook. Theory, Implementation and Applications, Cambridge.

Bannister, D. (1981). Personal construct theory and research method in Reason, P. and Rowan, J. (Eds.), in Human inquiry: A sourcebook of new paradigm research pp. 191-200. Chichester, UK: John Wiley and Sons.

Berners-Lee, T., Hendler, J., Lassila, O. (2001). The Semantic Web. Scientific American, 284(5), 3443.

Brown, A. and Voltz, B. (2005). Elements of effective e-learning design. International Review of Research in Open and Distance Learning 6(1).

Buzza, D., Bean, D., Harrigan, K. and Carey, T. (2005). Learning Design Repositories: Adapting Learning Design Specifications For Shared Instructional Knowledge. Canadian Journal of Learning and Technology, 30(3).

Conole, G., Dyke, M., Oliver, M. and Seale, J. (2004). Mapping pedagogy and tools for effective learning design. Computers \& Education, 43(1-2), 17-33.

Dodero, J.M., Aedo, I. and Díaz, P. (2002). Participative Knowledge Production of Learning Objects for e-Books. The Electronic Library, 20(4), pp. 296-305.

Friesen, N. (2005). Interoperability and Learning Objects: An Overview of E-Learning Standardization. Interdisciplinary Journal of Knowledge and Learning Objects 1(1), 23-31.

Gruber T. (1995). Towards principles for the design of ontologies used for knowledge sharing. International Journal of Human-Computer studies, 43 (5/6), 907 - 928.

Hatchuel, A., (2002) Towards Design Theory and expandable rationality : The unfinished program of Herbert Simon, Journal of Management and Governance, 5:3-4, 2002. 
Holmes, J. (2005). Designing agents to support learning by explaining. Computers and Education (to appear).

IEEE Learning Technology Standards Committee (2002). Learning Object Metadata (LOM), Final Draft Standard, IEEE 1484.12.1-2002.

IMS (2003) IMS Learning Design Information Model, Version 1.0 Final Specification, 20 January 2003.

Kaptelinin, V., Kuutti, K., Bannon, L. Activity Theory: Basic Concepts and Applications. In Blumenthal et al. (Eds.) Human-Computer Interaction. Lecture Notes in Computer Science. Springer, 1995.

Koper, R. (2004). Use of the Semantic Web to Solve Some Basic Problems in Education: Increase Flexible, Distributed Lifelong Learning, Decrease Teacher's Workload. Journal of Interactive Media in Education, 2004 (6).

D. Lenat, Cyc: A Large-Scale Investment in Knowledge Infrastructure, Communications of the ACM 38(11) (1995) 33\{38.

McGreal, R. (2004). Learning Objects: A Practical definition. International Journal of Instructional Technology and Distance Learning 1(9), 21-32.

Packer, M. and Goicoechea, J. (2000). Sociocultural and constructivist theories of learning: ontology, not just epistemology. Educational Psychologist, 35(4), 227-241.

Palmer, J. (2001). Fifty major thinkers on education. London and New York: Routledge.

Polsani, P. R. (2003). Use and Abuse of Reusable Learning Objects. Journal of Digital information, $3(4)$.

Rothwell, W. and Kazanas, H. (1992). Mastering the instructional design process. Jossey-Bass, San Francisco, CA.

Sánchez-Alonso, S. and Sicilia, M. A. (2004). Relationships and commitments in learning object metadata. In Proceedings of the 5th International Conference on Information Technology Based Higher Education and Training: ITHET 2004. Istambul, Turkey.

Sicilia, M. A. and Lytras, M. (2005). On the representation of change according to different ontologies of learning. International Journal of Learning and Change, 1(1).

Sicilia, M.A., Lytras, M., Rodríguez, E. and García, E. (2005). Integrating Descriptions of Knowledge Management Learning Activities into Large Ontological Structures: A Case Study. Data and Knowledge Engineering (to appear).

M.A. Sicilia and E. García. On the Convergence of Formal Ontologies and Standardized eLearning. Journal of Distance Education Technologies 3(2), 2005, pp. 13-29.

Sicilia, M.A., García, E. (2004) Fuzzy Group Models for Adaptation in Cooperative Information Retrieval Contexts Lecture Notes in Computer Science 2932 Springer, 324-334. 
M Tennant (1991) Expertise as a dimension of adult development. New Education, 13, 1, pp 4955.

Vanderdonckt, J. (1999). Development milestones towards a tool for working with guidelines. Interacting with Computers 12(2): 81-118.

Wand, Y.; Weber, R. (1995) On the deep structure of information systems. Information Systems Journal (5), 1995, pp. 203-223.

Wiley, D. A. (2001). The Instructional Use of Learning Objects. Association for Educational Communications and Technology, Bloomington. 